\title{
ANTIOXIDANT ACTIVITIES OF SOME LESS UTILIZED EDIBLE FRUITS
}

\author{
SUMITA DASGUPTA1 ${ }^{*}$, MAITRY PANDYA ${ }^{1}$, NIRALI PATEL
}

${ }^{1}$ Biotechnology Department, Bhagwan Mahavir College of Science and Technology, New City Light Road, Surat 395017 Email: sumitarup@gmail.com

Received: 22 May 2017, Revised and Accepted: 22 Jul 2017

\begin{abstract}
Objective: The objective of the present study was to evaluate the total phenolic (TPC) and flavonoid content (TFC) of five less utilized fruits such as Aegle marmelos, Spondias pinnata, Limonia acidissima, Averhoa carambola, Crescentia cujete and was compared with Phyllanthus emblica, (Amla) well known for its antioxidant activities. Total phenolic and flavonoid contents of samples were correlated with antioxidant activities like 1,1-Diphenyl-2Picryl-Hydrazyl (DPPH) free radical scavenging assay, Ferric reducing antioxidant potential (FRAP) assay and total antioxidant capacity (TAC).

Methods: The total phenolic of each fruit extract were determined by the Folin-Ciocalteu method with some modifications and the total flavonoids were estimated by Aluminum trichloride colourimetric method. The DPPH antioxidant assay, The FRAP assay and TAC were determined spectrophotometrically.

Results: The total phenolics were expressed as $\mathrm{mg} / 100 \mathrm{~g}$ Gallic acid equivalent (mg GAE/100 gm) and the total flavonoids were expressed as $\mathrm{mg} / 100 \mathrm{~g}$ Quercetin equivalent (mg QE/100 gm). TPC was found to be maximum in Spondias pinnata with $142.16 \mathrm{mg}$ GAE/100 gm where as TFC was maximum in Phyllanthus emblica with $91.1 \mathrm{mgQE} / 100 \mathrm{gm}$. DPPH radical scavenging activity was expressed $\mathrm{n}$ percentage(\%), FRAP values expressed as mg/100g Ascorbic equivalent (AAE) and the total antioxidant activity was expressed as mg/100g Ascorbic equivalent. Maximum DPPH radical scavenging activity was shown by Spondias pinnata (93.75\%), FRAP values were maximum in Phyllanthus emblica with 72.6 mg AAE/100 gm and total antioxidant capacity was found to be highest in Spondias pinnata (50.1 mg AAE/100 gm).
\end{abstract}

Conclusion: Spondias pinnata, an underutilized fruit, was found to be promising with antioxidant activities comparable to Phyllanthus emblica

Keywords: Less utilized fruits, Total phenolic, Total flavonoid, Spondias pinnata

(C) 2017 The Authors. Published by Innovare Academic Sciences Pvt Ltd. This is an open access article under the CC BY license (http://creativecommons.org/licenses/by/4.0/]

DOI: http://dx.doi.org/10.22159/ijcpr.2017v9i5.22132

\section{INTRODUCTION}

Studies have shown that fruits are the sources of diverse phytochemicals many of which display antioxidant properties [1]. The natural antioxidants present in fruits reduce the level of oxidative stress [2] and has been scientifically shown that by combating oxidative stress many diseases such as heart disease, cancer, diabetes, hypertension, stroke and Alzheimer's disease can be prevented $[3,4]$. The antioxidative effect of the fruit is mainly due to phenolic components [5]. Presently much attention has been paid to the lesser known fruits with the principal purpose of utilizing them as a functional food and as ingredients in nutraceuticals [6, 7]. The food security becomes vulnerable when it is dependent on a few numbers of the crop [8]. Enriching the shrinking resource base of our food basket is urgently required [9] and this can be achieved by exploiting and utilizing the wild and less utilized sources. The present study was carried out with five less utilized fruits like Aegle marmelos (L.) Corr Serr, Spondias pinnata (L. f.) Kurz, Limonia acidissima L., Averhoa carambola L. and Crescentia cujete collected from different parts of South Gujarat. The Total Phenolic Content (TPC), Total Flavonoid Content (TFC), DPPH radical scavenging activity, Total Antioxidant Capacity (TAC), and Ferric Reducing Antioxidant Potential (FRAP) of the above-mentioned fruits were evaluated. total phenolic and Flavonoid contents of samples were correlated with the different antioxidant activities. Phyllanthus emblica $L$ commonly known "Amla", well known for its rich polyphenol content and antioxidant properties was used as positive control $[10,11]$.

\section{MATERIALS AND METHODS}

\section{Chemicals and reagents}

Folin-Ciocalteu, sodium carbonate, aluminum trichloride $\left(\mathrm{AlCl}_{3}\right)$ methanol, DPPH, deionized distilled water, ethanol, hydrochloric acid $(\mathrm{HCl})$, potassium ferricyanide sodium dodecyl sulfate (SDS), ferric chloride $\left(\mathrm{FeCl}_{3}\right)$, ammonium molybdate, sodium phosphate, Ascorbic Acid were purchased from Hi-meida, India. Gallic acid and Quercetin were purchased from Sigma.

\section{Instruments}

Hot air oven grinder, digital balance water bath, hot plate, magnetic stirrer, centrifuge, thermometer, microwave oven, spectrophotometer, refrigerator, glassware (conical flasks, beakers, test tubes, petri plates, glass rod), micro pipettes.

\section{Fruit sample collection and extract preparation}

Fresh fruit samples of Aeglemarmelos, Spondias pinnata, Limonia acidissima, Averrhoa carambola, Crescentia cujete and Phyllanthus emblica were collected from Dharampur and nearby areas of South Gujarat in the month of December-January. Fruits were botanically identified with the help of local flora and authenticated by experts. All the fruits were washed with running water and then finally with distilled water. The edible portion of fruits $(1 \mathrm{gm})$ was homogenized with $10 \mathrm{ml}$ of an aqueous methanol solution (70\% methanol). The homogenate was stirred with a magnetic stirrer at $900 \mathrm{rpm}$ at room temperature for $30 \mathrm{~min}$. The extract was centrifuged at $3000 \mathrm{rpm}$ for $20 \mathrm{~min}$. The supernatant was removed and filtered with Whatman filter paper (No.1). The process under vacuum and dissolved in methanol: water (4:1) ratio [7].

\section{Determination of total phenolic}

The total phenolic of each fruit extract was determined by the FolinCiocalteu method with some modifications [7]. The diluted aqueous solution of each extract $(0.5 \mathrm{ml})$ was mixed with Folin Ciocalteu reagent $(0.2 \mathrm{~N}, 2.5 \mathrm{ml})$. This mixture was allowed to stand at room temperature for $5 \mathrm{~min}$ and then sodium carbonate solution $(75 \mathrm{~g} / \mathrm{l}$ in water, $2 \mathrm{ml}$ ) was added. After $2 \mathrm{~h}$ of incubation, the absorbance was measured at $760 \mathrm{~nm}$ against a water blank. A standard calibration curve was plotted using Gallic acid.

\section{Determination of total flavonoid}

The total flavonoids were estimated by aluminium trichloride colorimetric method [12]. A diluted methanolic solution (2 ml) of each 
fruit extract was mixed with a solution $(2 \mathrm{ml})$ of AlCl3 in methanol (2 $\%$ ). The absorbance was read at $415 \mathrm{~nm}$ after 10 min against a blank sample consisting of a methanol $(2 \mathrm{ml})$ and with AlCl3. Quercetin was used as reference compound to produce the standard curve.

\section{DPPH free radical scavenging assay}

The DPPH antioxidant assay was determined as described by [13]. Briefly, $0.1 \mathrm{mmol}$ DPPH $(1 \mathrm{ml})$ dissolved in ethanol was added to an ethanol solution $(3 \mathrm{ml})$ of the tested compound at different concentrations $(0,40,60,80,100 \mu \mathrm{g} / \mathrm{ml})$. An equal volume of ethanol was added in the control test. The mixture was shaken vigorously and allowed to stand at room temperature for $30 \mathrm{~min}$. Then the absorbance at $517 \mathrm{~nm}$ was measured with a UV spectrophotometer. The percentage of scavenging of DPPH was then calculated in the following way:

DPPH scavenging effect $(\%)=[1-($ Test sample absorbance $/$ blank sample absorbance) $] \times 100(\%)$

\section{Modified ferric reducing antioxidant potential (FRAP) assay}

The FRAP assay was done according to Oyaizu method with some modifications [14]. To $0.1 \mathrm{ml}$ of each fruit extract, $0.9 \mathrm{ml} 96 \%$ ethanol, $5 \mathrm{ml}$ of distilled water, $1.5 \mathrm{ml}$ of $1 \mathrm{M}$ Hydrochoric acid $(\mathrm{HCl})$, $1.5 \mathrm{ml}$ of $1 \%$ potassium ferricyanide $\mathrm{K}_{3}\left[\mathrm{Fe}(\mathrm{CN})_{6}\right], 0.5 \mathrm{ml}$ of $1 \%$ Sodium dodecyl sulfate (SDS) and $0.2 \% 0.5 \mathrm{ml}$ ferric chloride $\left(\mathrm{FeCl}_{2}\right)$ were added to each extract. the mixture was boiled in a water bath at $50{ }^{\circ} \mathrm{C}$ for $20 \mathrm{~min}$ after boiling the mixture was rapidly cooled and mixed well. The increase in the absorbance at $750 \mathrm{~nm}$ was used to measure the reducing power of the fruit extract. Ascorbic acid was used as a positive control.

\section{Total antioxidant capacity (TAC) by phospho- molybdenum method}

The total antioxidant capacity of the methanol extract was evaluated by the phosphomolybdenum method according to the procedure described by [15]. A $0.2 \mathrm{ml}$ extract was combined with $2 \mathrm{ml}$ of reagent solution $(0.6 \mathrm{M}$ sulfuric acid, $28 \mathrm{mmol}$ sodium phosphate and $4 \mathrm{mmol}$ ammonium molybdate). The absorbance of the reaction mixture was measured at $695 \mathrm{~nm}$ using a spectrophotometer against a reagent blank after incubation it at $95^{\circ} \mathrm{C}$ for $90 \mathrm{~min}$ and cooling to room temperature. Reagent $(2 \mathrm{ml})$ in the place of the extract was used as the blank. The antioxidant activity is expressed as the number of mg/gm equivalent of Ascorbic Acid. (AAE).

The results of the all these study were presented as the mean of three determinations along with standard deviation. Statistical analysis was done using MS Excel software (CORREL Statistical function).

\section{RESULTS}

\section{Total phenolic and flavonoids content}

The total phenolic was expressed as $\mathrm{mg} / 100 \mathrm{~g}$ Gallic acid equivalent (mg GAE/100 gm) using the standard curve equation: $\mathrm{y}=0.0087 \mathrm{x}$
$+0.018, \mathrm{R}^{2}=0.9994$, Where $\mathrm{y}$ is an absorbance at $760 \mathrm{~nm}$ and $\mathrm{x}$ is the total phenolic content of the fruits (fig. 1).

In the present study, all the fruits were found to be quite rich in phenolic. The total content of phenolic ranges from 101.20 \pm 2.39 in Crescentia cujete to $142.16 \pm 0.7$ as found in Spondias pinnata (table 1). The total flavonoids were expressed as $\mathrm{mg} / 100 \mathrm{~g}$ Quercetin equivalent ( $\mathrm{mg} \mathrm{QE} / 100 \mathrm{gm}$ ) using the standard curve equation: $\mathrm{y}=$ $0.005250 x+0.123, R^{2}=0.998$, Where $y$ is an absorbance at $415 \mathrm{~nm}$ and $\mathrm{x}$ is total flavonoids content (fig. 2). Total flavonoids varied from $42.4 \pm 0.41 \mathrm{mgQE} / 100 \mathrm{gm}$ in Averrhoa carambola to $91.1 \pm 0.55$ $\mathrm{mgQE} / 100 \mathrm{gm}$ in Phyllanthus emblica (table 1). Variation in total phenolic and flavonoids was observed among the studied fruits. TPC was higher in Spondias pinnata where as TFC was maximum in Phyllanthus emblica (table 1).

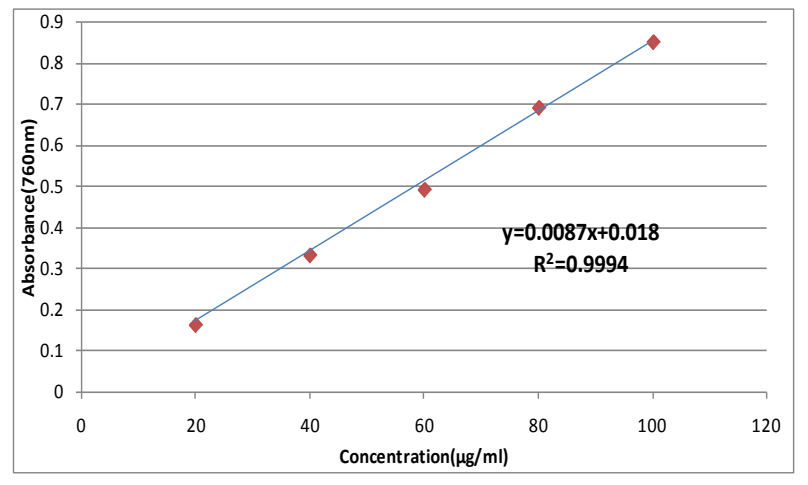

Fig. 1: Standard curve of gallic acid

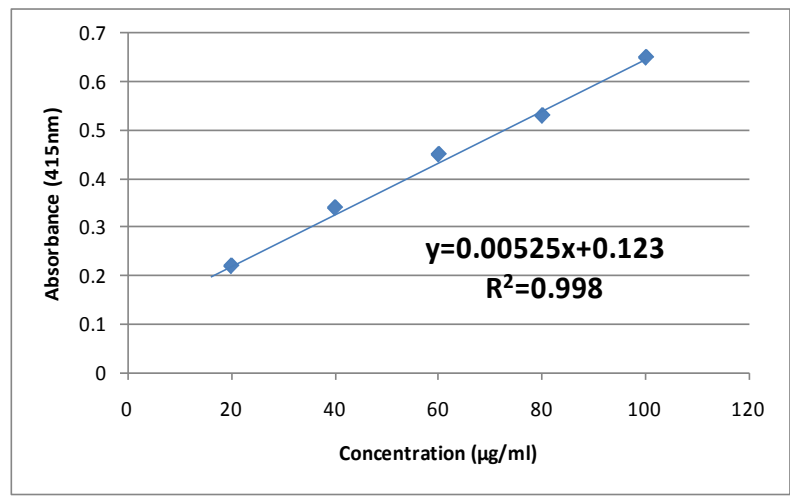

Fig. 2: Standard curve of quercetin acid

Table 1: Total phenolic and total flavonoid of the studied fruits

\begin{tabular}{lcl}
\hline Fruit species & Total phenolics (mgGAE/100 gm) & Total flavonoids (mgQE/100 gm) \\
\hline Phyllanthus emblica & $130.33 \pm 1.8$ & $\mathbf{9 1 . 1 \pm 0 . 5 5}$ \\
Spondias pinnata & $142.16 \pm 0.7$ & $77.10 \pm 0.43$ \\
Aegle marmelos & $117.33 \pm 1.3$ & $52.2 \pm 0.30$ \\
Averrhoa carambola & $104.32 \pm 2.42$ & $42.4 \pm 0.41$ \\
Limonia acidissima & $103.66 \pm 3.01$ & $47.7 \pm 0.35$ \\
Crescentia cujete & $101.20 \pm 2.39$ & $49.1 \pm 0.7$ \\
\hline
\end{tabular}

Each value represents the mean of three replicated+Standard Deviation.

DPPH free radical scavenging assay, modified ferric ion reducing assay and total antioxidant capacity

In the present study, all the extracts showed free radical scavenging properties at different levels. Maximum DPPH radical scavenging activity was shown by Spondias pinnata $(93.75 \pm 1.06)$ followed by Phyllanthus emblica (93. 5 \pm 1.76$)$. Averrhoa carambola showed the least activity of $77.5 \pm 3.53$ (table 2 ).
FRAP values were obtained by comparing the absorbance change at $750 \mathrm{~nm}$ in test reaction mixtures with those containing ferrous ions in a known concentration of Ascorbic acid and were expressed as $\mathrm{mg} / 100 \mathrm{~g}$ Ascorbic equivalent (AAE) using the standard curve equation: $\mathrm{y}=0.0291 \mathrm{x}+0.2348, \mathrm{R}^{2}=0.966$ (fig. 3 ). The value ranges from $30.6 \pm 0.11 \mathrm{mg} \mathrm{AAE} / 100 \mathrm{gm}$ in Limonia acidissima to $72.6 \pm 0.4$ mg AAE/100 gm in Phyllanthus emblica (table 2). Spondias pinnata also showed very high activity (70.0 $\pm 0.2 \mathrm{mg} \mathrm{AAE} / 100 \mathrm{gm})$. 
The total antioxidant activity is expressed as the number of equivalents of ascorbic acid. The value was expressed as $\mathrm{mg} / \mathrm{g}$ Ascorbic equivalent using the standard curve equation: $\mathrm{y}=$ $0.00415 x+0.075, R^{2}=0.9800$ (fig. 4).

Among the extracts of the different fruits undertaken for the study, total antioxidant capacity was found to be highest in Spondias pinnata $(50.1+0.5 \mathrm{mg}$ AAE/100 gm) followed by Phyllanthus emblica $(46.0+1.2 \mathrm{mg} \mathrm{AAE} / 100 \mathrm{gm})$. The least value of $10.2+0.5$ mg AAE/gm was found in Averrhoa carambola (table 2).

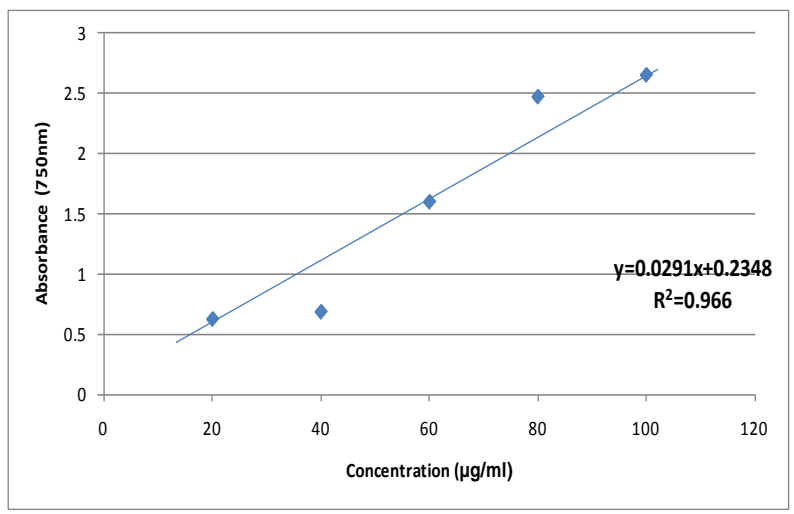

Fig. 3: Standard curve of ascorbic acid for for FRAP assay

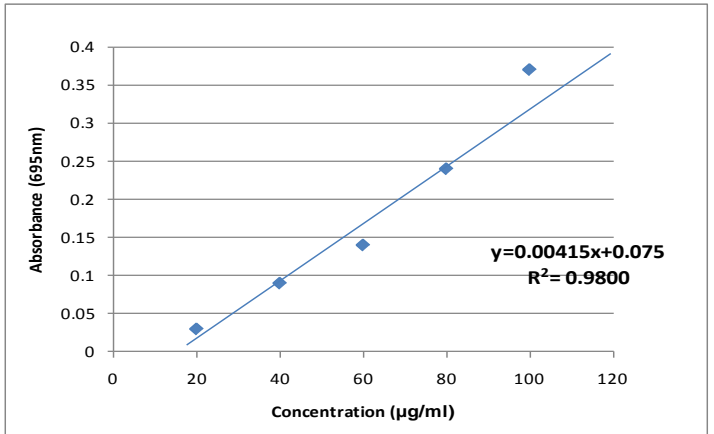

Fig. 4: Standard curve of ascorbic acid for TAC

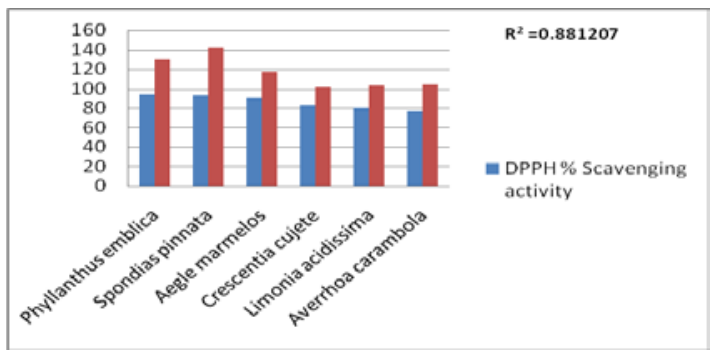

Fig. 5: Linear correlation between DPPH scavenging activity and total phenolics

Table 2: DPPH Free radical scavenging assay, FRAP assay and TAC of the studied fruits

\begin{tabular}{llll}
\hline Fruit species & $\begin{array}{l}\text { DPPH \% scavenging } \\
\text { activity }\end{array}$ & $\begin{array}{l}\text { Ferric reducing power assay (mg AAE/100 } \\
\text { gm) }\end{array}$ & $\begin{array}{l}\text { Total antioxidant capacity (mg AAE/100 } \\
\text { gm) }\end{array}$ \\
\hline Phyllanthus emblica & $93.5 \pm 1.76$ & $\mathbf{7 2 . 6 \pm 0 . 4}$ & $46+1.2$ \\
Spondias pinnata & $\mathbf{9 3 . 7 5} \pm \mathbf{1 . 0 6}$ & $70.0 \pm 0.2$ & $\mathbf{5 0 . 1 + 0 . 5}$ \\
Aegle marmelos & $90.62 \pm 1.94$ & $67.6 \pm 0.1$ & $18.5+0.7$ \\
Crescentia cujete & $83.25 \pm 1.06$ & $60.6 \pm 0.5$ & $23.1+0.1$ \\
Limonia acidissima & $80.00 \pm 0.71$ & $50.0 \pm 0.15$ & $30.0+0.4$ \\
Averrhoa carambola & $77.5 \pm 0.53$ & $30.6 \pm 0.11$ & $10.2+0.5$ \\
\hline
\end{tabular}

Each value represents the mean of three replicates+Standard deviation

\section{DISCUSSION}

Phenolics are a class of antioxidant agents with very strong redox properties, acting as hydrogen donors, singlet oxygen quenchers, metal chelators and scavengers of free radicals $[16,17]$. In the present study, the methanolic extract of Spondias pinnata was found to possess maximum total phenolic. The high content of total phenolic of $S$. pinnata was also reported in a previous work conducted in Nepal [18]. Flavonoids also possess high antioxidant activity which is due to their ability to reduce free radical formation and to scavenge free radicals [19]. The free radical scavenging activity of methanolic extracts of different fruits was studied by their ability to reduce the DPPH. DPPH is a stable free radical and accepts an electron or hydrogen radical to become a stable diamagnetic molecule [20]. A freshly prepared DPPH solution is of deep purple colour with an absorption maximum at $517 \mathrm{~nm}$ and in the presence of antioxidant this colour disappears due to quenching of DPPH free radicals and converting them into a colourless product i.e. 2, 2diphenyl-1-hydrazine. Antioxidant mechanism performed by providing hydrogen atoms or [21]. In the FRAP assay, the antioxidants reduce $\mathrm{Fe}^{3+}$ to $\mathrm{Fe}^{2+}$. This ion then conjugates with Ferricyanide ion to form Prussian blue coloured product which was spectrophotometrically measured at $750 \mathrm{~nm}$ wavelength. [22]. Total antioxidant capacity by phospho- molybdenum method assay is based on the reduction of Mo (VI) to Mo (V) by the sample analyte and the subsequent formation of green phosphate/Mo (V) complex at acidic $\mathrm{pH}$. In the present study, the strong and positive correlation was observed between total phenolics and total flavonoids of the undertaken fruits with antioxidant assays like DPPH radical scavenging activity, FRAP assay and with total antioxidant capacity (TAC). Maximum correlation $\left(\mathrm{R}^{2}=0.881\right)$ was observed between total phenolics and DPPH radical scavenging activity (fig. 5).

This suggests that $88 \%$ of the antioxidant potential with respect to the ability to scavenge DPPH radical results from the TPC of the fruits undertaken for the study. It was also observed that Spondias pinnata which has the highest phenolic content possess maximum DPPH radical scavenging activity as compared to other fruits undertaken for the study (table 2). In a previous work with different leaf extracts of blackberry species, similar types of the result of high DPPH radical scavenging activity correlating with high phenol content was observed [23].

The results in the present study indicate that though phenol and flavonoids are the major contributors of antioxidant activities antioxidant activities of the fruits are not limited to the phenolic only, other secondary compounds such as ascorbic acid, $\beta$-carotene, $\alpha$-carotene and different xanthophylls might be playing a significant role for the antioxidant activity [24].

\section{CONCLUSION}

The present study showed that all the less known edible fruits which were never compared together for their antioxidant activities have immense potential as a source of antioxidant. Of these, Spondias pinnata, a wild edible fruit [25] was found to possess higher TPC value than that of Amla, with equally significant TFC value and antioxidant capacity. 
However, more detailed study with respect to phytochemical content and other in vivo assays are required to establish these less known edible fruits as powerful antioxidants.

Sustainable use of wild fruits needs to be promoted. Wider and sustained acceptance of wild fruits as important dietary components must be stimulated to solve the problems of food scarcity [26].

\section{CONFLICT OF INTERESTS}

None of the authors declared any conflict of interest.

\section{ACKNOWLEDGEMENT}

We are indebted to Dr. P. V. Desai, Principal, and Dr. S. Desai, Vice Principal, Bhagwan Mahavir College of Science and technology for supporting us and providing us the necessary facilities.

\section{AUTHOR CONTRIBUTION}

The above study was carried out by research students Ms. Maitry Pandya and Ms. Nirali Patel under the supervision of Dr. Sumita Dasgupta.

\section{REFERENCES}

1. Scalzo J, Politi A, Pellegrini N, Mezzetti B, Battino M. Plant genotype affects total antioxidant capacity and phenolics contents in fruit. Nutrition 2005;21:207-13.

2. Hassimotto NMA, Genovese MI, Lajolo FM. Antioxidant activity of dietary fruits, vegetables and commercially frozen fruit pulps. J Agric Food Chem 2005;53:2928-35.

3. Abdel-Hameed ESS. Total phenolics contents and free radical scavenging activity of certain eyptian ficus species leaf samples. Food Chem 2009;114:1271-7.

4. Giasson BI, Ischiropoulos H, Virginia M, Lee Y, Trojanowski JQ. The relationship between oxidative/nutritive stress and pathological inclusions in Alzheimer's and Parkinson's diseases. Free Radical Biol Med 2002;32:1264-75.

5. Pietta PG. Flavonoidss as antioxidants. J Nat Prod 2000; 63:1035-42.

6. Ozga JA, Saeed A, Wismer W, Reinecke DM. Characterization of cyanidin-and quercetin-derived Flavonoids and other Phenolicsss in mature saskatoon fruits (Amelanchier alnifolia Nutt.). J Agric Food Chem 2007;55:10414-24.

7. Karuppusamy S, Muthuraja G, Rajasekaran KM. Antioxidant activities of selected lesser known edible fruits of from Western Ghats of India. Indian J Nat Prod Resources 2011;2:174-8.

8. Hegazy AK, Al-Rowaily SL, Faisal M, Alatar AA, El-Bana MI, Assaeed AM. Nutritive value and antioxidant activity of some edible wild fruits in the Middle East. J Med Plants Res 2013;7:938-46.

9. Nazarudeen A. Nutrional composition of some lesser-known fruits used by the ethnic communities and local folks of Kerala. Indian J Traditional Knowledge 2010;9:398-402.

10. Bhattacharya A, Chatterjee A, Ghosal S, Bhattacharya SK. Antioxidant activity of active tannoid principles of Emblica officinalis (amla). Indian J Exp Biol 1999;37:676-80.
11. Khopde SM, Indira Priyadarsini K, Mohan H, Gawandi VB, Satav JG, Yakhmi JV, et al. Characterizing the antioxidant activity of amla (Phyllanthus emblica) extract, Curr Sci 2001;81:185-90.

12. Arvouet-Grand A, Vennat B, Pourrat A, Legret P. Standardisation d'un extrait de propolis et identification des principaux. J Pharm Belgique 1994;49:462-8.

13. Shimada K, Fujikawa K, Yahara K, Nakamura T. Antioxidative properties of xanthan on the autoxidation of soybean oil in cyclodextrin emulsion. J Agric Food Chem 1992;40:945-8.

14. Oyaizu M. Studies on the product of browning reaction prepared from glucose amine. Jpn J Nutr 1986;44:307-15.

15. Prieto $P$, Pineda $M$, Anguilar $M$. Spectrophotometric quantitation of antioxidant capacity through the formation of a phosphomolybdenum complex: specific application to the determination of Vitamin E. Anal Biochem 1999;269:337-41.

16. Rice-Evans CA, Miller NJ, Bolwell PG, Bramley PM, Pridham JB. The relative antioxidant activities of plant-derived poly phenolics flavonoids. Free Radical Res 1995;22:375-83.

17. Olajire AA, Azeez L. Total antioxidant activity, Phenolics, Flavonoids and ascorbic acid contents of Nigerian vegetables. Afr J Food Sci Technol 2011;2:22-9.

18. Chalise JP, Acharya K, Gurung N, Bhusal RP, Gurung R, SkalkoBasnet $\mathrm{N}$, et al. Antioxidant activity and polyphenol content in edible wild fruits from Nepal. Int J Food Sci Nutr 2010;4:425-32.

19. Pietta PG. Flavonoidss as antioxidants. J Nat Prod 2000;63:1035-42.

20. Soares JR, Dinis TC, Cunha AP, Almeida LM. Antioxidant activity of some extracts of Thymus zygi. Free Radical Res 1997;26:469-78.

21. Ferreira ICFR, Bptista P, Vilas-Boas M, Barros L. Free-radical scavenging capacity and reducing the power of wild edible mushrooms from northeast portugal: individual cap and stipe activity. Food Chem 2007;100:1511-6.

22. Shanmugam S, Kumar Sathish T, Panneer Selvam K, Modified ferric ion reducing antioxidant power assay (Modified FRAP Assay). In: laboratory handbook on Biochemistry PHI Learning Pvt. Ltd; 2010. p. 116-7.

23. Gzella AG, Makuch MD, Matławska I. DPPH radical scavenging activity and Phenolics compound content in different leaf extracts from selected blackberry species. Acta Biol Cracov Ser Bot 2012;54:32-8.

24. Kondo S, Kittikorn M, Kanlayanarat S. Pre harvest antioxidant activities of tropical fruit and the effect of low-temperature storage on antioxidants and jasmonates. Postharvest Biol Technol 2005;36:309-18.

25. Khomdram S, Arambam S, Shantibala Devi G. Nutritional profiling of two underutilized wild edible fruits Elaeagnus pyriformis and Spondias pinnata. Ann Agric Res New Series 2014;35:129-35.

26. Deshmukh BS, Waghmode A. Role of wild edible fruits as a food resource: Traditional knowledge. Int J Pharm Life Sci 2011;2:919-24.

\section{How to cite this article}

- Sumita Dasgupta, Maitry Pandya, Nirali Patel. Antioxidant activities of some less utilized edible fruits. Int J Curr Pharm Res 2017;9(5):28-31. 